\title{
Retractions of research papers by authors from the Arab region (1998-2018)
}

\author{
Saif Aldeen AIRyalat (Corresponding author) \\ Department of Ophthalmology, The University of Jordan, Amman, Jordan; saifryalat@yahoo.com; ORCID 0000-0001-5588-9458
}

\author{
Muayad Azzam, Abdallah Massad, Dana Alqatawneh \\ The University of Jordan, Amman, Jordan
}

\section{DOI: 10.3897/ese.2020.e51002}

\begin{abstract}
Objective: To provide an overview of retractions of research papers contributed by authors from the Arab region.

Method: Papers in which the first author was affiliated to an Arabian country were selected from the Retraction Watch database covering the period 1 January 1998 to 31 December 2018. The retrieved records were divided into nine categories based on the reasons for retraction.
\end{abstract}

Results: The search yielded 322 retractions, and the most frequent reason for retraction was plagiarism (34.5\%). The median time from publication to retraction was 14 (25\%-75\% percentile 5-30) months. The number of papers retracted each year as well as the number of papers published in a given year but subsequently retracted increased steadily over the 21 years. The proportion of retracted papers to the total number of published papers $(0.17 \%)$ was higher than the global proportion and was the highest for Algeria (1\%) and the lowest for Lebanon (0.03\%). Of the countries within the Arab region, 12 out of 14 countries showed either plagiarism or duplication as the most common reason for retraction; however, the countries differed in terms of the number of retractions and the time from publishing to retraction.

Conclusion: Plagiarism was the most common cause of retraction in the Arab countries. The increase in the number of papers retracted each year was probably because searches now extend farther in the past, whereas the increase in the number of papers published in a given year but subsequently retracted can be attributed to the overall increase in the number of papers published.

Keywords: Duplication, fabrication, plagiarism; retraction, research ethics, scientific misconduct

\section{Introduction}

Research journals, particularly peer reviewed journals, have served as the main means of scientific communication ever since their appearance. Peer review is as a mechanism to control the quality of research papers. ${ }^{1,2}$ Over time, journals have come to depend on peer review, which confers credibility of their contents-so much so that publishing is now considered as important as research itself., ${ }^{3,4}$ Several other factors, the most important of which is the linking of publications to career advancement in certain fields, have greatly increased the number of papers being published as well as the pressure on researchers to publish as many papers as possible. ${ }^{4-6}$

The impact on research literature of the increased publishing activity and greater pressure has been the subject of many studies, some of which have shown the trade-off between quantity and quality, ${ }^{7-9}$ with some researchers using scientific publications as a currency for promotion, regardless of their quality. On the other hand, other studies have countered this claim and shown that highly productive researchers, as assessed by the number of publications, also publish highquality papers, as assessed by the number of publications in journals with high impact factors. ${ }^{6,10}$ Unfortunately, the increase in the volume of scientific literature is matched by the number of mistakes found in research papers. Some studies attribute most of these mistakes to misconduct and deliberate fraud, ${ }^{11,12}$ whereas other studies attribute them to errors. ${ }^{13,14}$ Some instances of misconduct and some errors remain undetected during the publication process and thus become part of the final published version served to readers and of the body of literature. To remedy the situation, journals publish corrections or errata subsequently or, in extreme cases, retract papers altogether to purge the literature as much as possible of inaccuracies and false information. ${ }^{15}$

The Arab world has faced, and continues to face, several obstacles to contributing to research literature and accounts for less than $1 \%$ of the total biomedical citations. ${ }^{16}$ Even within the Middle East, the share of Arab countries in biomedical publications is less than that of other economically comparable countries in that region, ${ }^{17}$ although it must be admitted that conditions in the Arab region in terms of research are less than optimal. Aware that it has lagged behind, the Arab region is keen to step up its contributions to scientific literature and to bridge the regional and global gap. ${ }^{18,19}$ Lest the pressure to publish should lead to misconduct and errors, eventually leading to retractions, it is important to highlight this threatwhich is why the present study sought to examine the current status of retractions from the Arab region.

\section{Methods}

Papers in which the first author was affiliated to an Arabian country were selected from the Retraction Watch database (RWD) covering the period 1 January 1998 to 31 December 2018. The retrieved records were divided into nine categories based on the reasons for retraction. 


\section{Countries}

The following fifteen countries were included in the study because each had at least one retraction during the study period: Bahrain, Egypt, Iraq, Jordan, Kuwait, Lebanon, Libya, Morocco, Oman, Palestine, Qatar, Saudi Arabia, Sudan, Syria, and United Arab Emirates.

\section{Search for retractions}

The number of publications in PubMed (https://www.ncbi.nlm. nih.gov/pubmed/) for each country was counted by looking for affiliations within that country: using the advanced search feature in PubMed, we first specified the countries and then restricted the search to the period 1998-2018.

\section{Retraction Watch database}

Established in August 2010, the RWD (retractionwatch.com) maintains an up-to-date list of retracted papers. We searched the database and defined duration as the duration, in months, between publication and retraction. The nine categories, each representing a different reason or related reasons for retraction, were as follows: no data available, duplication, plagiarism, author related (for example, author dispute), data related (for example, falsified or fabricated data), investigation related (for example, errors in the methods), review related (for example, fake peer review), or ethical (for example, non-approval on ethical grounds). Papers freely accessible to all were considered open-access papers.

\section{Statistical analysis}

We used SPSS ver. 21.0 (Chicago, USA) after entering all the data the into the package to obtain the relevant descriptive statistics including median values, $25 \%-75 \%$ percentiles for continuous variables (for example, duration between publication and retraction), and frequencies with percentages for nominal and ordinal variables (for example, retractions by publishers).

\section{Results}

The search yielded a total of 322 retractions from Arabian countries. The median duration from publication to retraction was 14 months, the range (25-75 percentile) being 5-30 months (Table 1). Of the total retractions, 308 (95.7\%) were published in open-access.

Table 1. Time lag between publication and retraction, by reasons for retraction in the Arab countries (1998-2018)

\begin{tabular}{|l|c|c|c|c|}
\hline Reason for retraction & Count & $\begin{array}{c}\text { Median } \\
\text { (months) }\end{array}$ & $\begin{array}{c}\mathbf{2 5 \%} \\
\text { quartile }\end{array}$ & $\begin{array}{c}\mathbf{7 5 \%} \\
\text { quartile }\end{array}$ \\
\hline Plagiarism & 111 & 14 & 5 & 32 \\
\hline Duplication & 85 & 24 & 11 & 46 \\
\hline Data related & 51 & 7 & 1 & 16 \\
\hline Author related & 44 & 10 & 5 & 24 \\
\hline Results related & 9 & 8 & 6 & 28 \\
\hline Investigation related & 8 & 13 & 11.5 & 19 \\
\hline Ethical & 8 & 13.5 & 7.5 & 26.5 \\
\hline Unknown & 4 & 8 & 2 & 12.5 \\
\hline Review related & 2 & 19.5 & 3 & 36 \\
\hline Total & 322 & 14 & 5 & 30 \\
\hline
\end{tabular}

When ranked by publisher, Elsevier topped the list, with 91 $(28.3 \%)$ retractions, followed, in that order, by Springer Nature (53; 16.4\%), Wiley-Blackwell $(21 ; 6.5 \%)$, Taylor \& Francis (15; $4.7 \%)$, and Wolters Kluwer (13; 4.1\%): the remaining 129 (40.1\%) retractions involved papers in journals from other publishers.

In terms of the number of authors for a given paper, 77 (23.9\%) of the retracted papers had one author; 64 (19.9\%) had two; 173 (53.7\%), three to nine; and 8 (2.5\%), ten or more. The oldest published paper had been published in 1992, which was retracted in 2009 (a duration of 208 months).

The frequency of retractions increased over the last few years, with 44 retractions in 2018 (Figure 1).

The detailed reasons for retraction are presented in Table 2. Plagiarism was the most common reason, accounting for 111 (34.5\%) retractions. A total of $128(39.8 \%)$ had more than one reason for retraction, with $10(3.1 \%)$ papers being retracted for four reasons.

In retractions related to data, the median duration was 7 months, the range being 1-16 months (Table 1), whereas the corresponding values for retractions related to duplication were 24 months (11-46 months).

When ranked by country, Egypt topped the list, with 142 (44.1\%) retractions, followed by Saudi Arabia (58; 18\%) (Table 3 ). The fastest retraction was that of a paper from Palestine (3 months, the range for that country being 1-5 months), whereas the slowest was from Sudan [24.5 months;range 19-30 months].

\section{Discussion}

Given that the study covered 21 years, the number of retractions (322) was low. This can be attributed to the overall low number of papers contributed by the Arab Region ${ }^{16}$ rather than to fewer errors or fewer instances of misconduct: the proportion of retractions to the total number of publications from the Arab region, which was $0.17 \%$, was higher than that reported for the world as a whole. ${ }^{20,21}$ In fact, El Rassi reported that the number of medical publications from the Arab region increased threefold between 2007 and 2016. ${ }^{18}$ The increase in retractions in our study for the corresponding period was also nearly threefold, from 8 to 22: although we are comparing the numbers for medical publications to those for all publications, the proportion indicates that the Arab world contradicts the global trend of increasing number of retractions, described by Steen et al: ${ }^{20}$ in other words, the increase in the number of retractions from the Arab region may reflect the overall increase in absolute terms but not in relative terms.

The annual number of retractions increased substantially, from one retraction in 1998 to 44 in 2018 (Figure 1). Some may argue that retractions are a positive sign, reflecting greater care by journals and their willingness to go farther back in the past to retract, ${ }^{21,22}$ whereas others believe this to be a matter of concern, ${ }^{23}$ particularly because misconduct and errors are underreported, and the efforts by journals and the scientific community may fall short. In the present study, the mean duration from publication to retraction was 23.6 months, a value similar to the values reported in other studies on retractions, ${ }^{20,21}$ indicating that journals are indeed digging deeper into their archives to extend the reach of retractions.

Misconduct was found to be the most common reason for retraction in two earlier studies. ${ }^{11,21}$ This observation applies to the Arab region as well: misconduct was also the most frequent 
reason for retraction in the present study and applied to more than half $(60.9 \%)$ of the retracted articles. Mohammed et al. found plagiarism as the most serious and common problem in scientific writing, ${ }^{24}$ and was the second most common reason $(34.5 \%)$ in the present study. Another study, which encompassed 20 countries with many retractions, including Tunisia and Egypt, also reported that at least one paper had been retracted on the grounds of duplication or plagiarism. ${ }^{24}$ In the present study too, the most frequent reason for retraction, found in 12 out of 14 of Arab countries, was duplication or plagiarism. Although the reasons for retraction were broadly similar between countries, the frequency and duration of retraction $\mathrm{s}^{25}$ varied to some extent. The majority of retractions $(62.1 \%)$ were accounted for by only two countries, namely Egypt (142; 44.1\%) and Saudi Arabia (58; $18 \%)$, whereas Palestine, Syria, and Sudan were the countries with the least number of retractions ( 2 each). The median duration was the shortest, only 3 months, for Palestine and the longest, 24.5 months, for Sudan, although both these countries had only two retracted papers each $(0.134 \%$ and $0.066 \%$, respectively).

It is important to mention the very high proportion (308; $95.7 \%$ ) in the present study of open-access journals, although we could not determine whether these journals charged a publishing fee, an aspect that deserves further study.

One of the most serious limitations of our study was that it focused on English-language papers to study an Arabic-speaking region, a shortcoming that should be addressed in future studies.

We conclude that the number of retractions from the Arab region has increased in the last decade, the most common reason for retraction being plagiarism. We believe that more stringent checks by journals for plagiarism would decrease the number of retractions in the coming years significantly.

Conflict of interest: The authors declare that they have no conflict of interest.

Acknowledgements: The authors would like to thank Dr Ivan Oransky and Retraction Watch (https://retractionwatch.com/) for providing the data used in this study.

\section{References}

1 Spier R. The history of the peer-review process. Trends in Biotechnology. 2002;20:357-358. https://doi.org/10.1016/S0167-7799(02)01985-6

2 Mulligan A, Hall L, Raphael E. Peer review in a changing world: an international study measuring the attitudes of researchers. Journal of the American Society for Information Science and Technology. 2013;64:132161. https://doi.org/10.1002/asi.22798

3 Zain SM, Ab-Rahman MS, Ihsan AKAM, et al. Motivation for research and publication: experience as a researcher and an academic. Procedia Social and Behavioral Sciences. 2011;18:213-219. https://doi.org/10.1016/j. sbspro.2011.05.030

4 Rawat S, Meena S. Publish or perish: where are we heading? Journal of Research in Medical Sciences. 2014;19:87-89.

5 Larsen PO, von Ins M. The rate of growth in scientific publication and the decline in coverage provided by Science Citation Index. Scientometrics 2010;84:575-603. https://doi.org/10.1007/s11192-010-0202-z

6 Sandström U, van den Besselaar P. Quantity and/or quality? The importance of publishing many papers. PLoS One 2016;11:e0166149. https://doi. org/10.1371/journal.pone.0166149

7 Hicks D, Wouters P, Waltman L, et al. Bibliometrics: the Leiden manifesto for research metrics. Nature 2015;520:429-431. https://doi.org/10.1038/520429a
8 James WA, Allen L, Belfiore E, et al. The metric tide: report of the independent review of the role of metrics in research assessment and management. 2015; Available from: www.nationalarchives.gov.uk/doc/ open-government-licence/version/2 (accessed: 26 Apr. 2019).

9 Dijstelbloem H, Huisman F, Miedema F, et al. Debate, progress and recommendations. 2014. Available from: www.scienceintransition.nl. (accessed 26 Apr. 2019)

10 Simonton DK. Creativity in science : chance, logic, genius, and zeitgeist. Cambridge University Press; 2004. 216 p. https://doi.org/10.1017/ CBO9781139165358

11 Fang FC, Steen RG, Casadevall A. Misconduct accounts for the majority of retracted scientific publications. Proceedings of the National Academy of Sciences U S A 2012;109:17028-17033. https://doi.org/10.1073/ pnas. 1212247109

12 Hesselmann F, Graf V, Schmidt M, et al. The visibility of scientific misconduct: a review of the literature on retracted journal articles. Current Sociology. 2017;65:814-845. https://doi.org/10.1177/0011392116663807

13 Nath SB, Marcus SC, Druss BG. Retractions in the research literature: misconduct or mistakes? Medical Journal of Australia. 2006;185:152-154. https://doi.org/10.5694/j.1326-5377.2006.tb00504.x

14 Wager E, Williams P. Why and how do journals retract articles? An analysis of Medline retractions 1988-2008. Journal of Medical Ethics 2011;37:567-570. https://doi.org/10.1136/jme.2010.040964

15 Teixeira da Silva JA, Dobránszki J. Problems with traditional science publishing and finding a wider niche for post-publication peer review. Accountability in Research. 2015;22:22-40. https://doi.org/10.1080/08989 621.2014 .899909

16 Tadmouri GO, Bissar-Tadmouri N. Biomedical publications in an unstable region: the Arab world, 1988-2002. Lancet (London, England) 2003;362:1766. https://doi.org/10.1016/S0140-6736(03)14868-4

17 Benamer HT, Bakoush O. Arab nations lagging behind other Middle Eastern countries in biomedical research: a comparative study. BMC Medical Research Methodology. 2009;9:26. https://doi. org/10.1186/1471-2288-9-26

18 El Rassi R, Meho LI, Nahlawi A, Salameh JS, Bazarbachi A, Akl EA. Medical research productivity in the Arab countries: 2007-2016 bibliometric analysis. Journal of Global Health. 2018;:020411. https://doi. org/10.7189/jogh.08.020411

19 El-Azami-El-Idrissi M, Lakhdar-Idrissi M, Ouldim K, et al. Improving medical research in the Arab world. Lancet (London, England) 2013; 382(9910):2066-7. https://doi.org/10.1016/S0140-6736(13)62692-6

20 Steen RG, Casadevall A, Fang FC. Why has the number of scientific retractions increased? PLoS One. 2013;8:e68397. https://doi.org/10.1371/ journal.pone.0068397

21 Moylan EC, Kowalczuk MK. Why articles are retracted: a retrospective cross-sectional study of retraction notices at BioMed Central. BMJ Open. 2016;6:e012047. https://doi.org/10.1136/bmjopen-2016-012047

22 Fanelli D. Why growing retractions are (mostly) a good sign. PLoS Medicine. 2013; 10(12):e1001563. https://doi.org/10.1371/journal. pmed. 1001563

23 Kakuk P. The legacy of the Hwang case: research misconduct in biosciences. Science and Engineering Ethics. 2009;15:545-562. https://doi. org/10.1007/s11948-009-9121-x

24 Mohammed RAA, Shaaban OM, Mahran DG, et al. Plagiarism in medical scientific research. Journal of Taibah University Medical Sciences. 2015;10:6-11. https://doi.org/10.1016/j.jtumed.2015.01.007

25 Amos KA. The ethics of scholarly publishing: exploring differences in plagiarism and duplicate publication across nations. Journal of the Medical Library Association. 2014 Apr;102(2):87-91. https://doi. org/10.3163/1536-5050.102.2.005 
AlRyalat SA, Azzam M, Massad A, Alqatawneh D. Retractions of research papers by authors from the Arab region (1998-2018). European Science Editing 2020;46.DOI: 10.3897/ese.2020.e51002

Table 2. Reasons for retraction in the Arab countries (1998-2018)

\begin{tabular}{|l|l|l|l|l|l|l|l|}
\hline First reason & Second reason & Third reason & Fourth reason \\
\hline Reason & $\mathbf{N}(\%)$ & Reason & $\mathbf{N}(\%)$ & Reason & N $\%)$ & Reason \\
\hline No data available & $4(1.2)$ & Duplication & $3(0.9)$ & Duplication & $2(0.6)$ & Plagiarism & N (\%) \\
\hline Duplication & $85(26.3)$ & Plagiarism & $14(4.3)$ & Plagiarism & $4(1.2)$ & Author related & $3(0.9)$ \\
\hline Plagiarism & $111(34.4)$ & Author related & $31(9.6)$ & Author related & $4(1.2)$ & Results related & $2(0.6)$ \\
\hline Author related & $44(13.6)$ & Data related & $25(7.7)$ & Data related & $2(0.6)$ & Investigation related & $1(0.3)$ \\
\hline Data related & $51(15.8)$ & Results related & $15(4.7)$ & Investigation related & $8(2.5)$ & Ethical & $3(0.9)$ \\
\hline Results related & $9(2.7)$ & Investigation related & $19(5.9)$ & Review related & $4(1.2)$ & & \\
\hline Investigation related & $8(24.8)$ & Review related & $7(2.1)$ & Ethical & $8(2.5)$ & & \\
\hline Review related & $2(0.6)$ & Ethical & $14(4.4)$ & & & & \\
\hline Ethical & $8(24.8)$ & & & & $32(9.9)$ & Total \\
\hline Total & $322(100)$ & Total & $128(39.7)$ & Total & & \\
\hline
\end{tabular}

Table 3. Retractions: number, time lag, and the most common reason, by country in the Arab countries (1998-2018)

\begin{tabular}{|l|l|l|l|l|l|l|l|}
\hline Country & $\begin{array}{l}\text { Number of } \\
\text { retractions }\end{array}$ & $\begin{array}{l}\text { Number of } \\
\text { publications }\end{array}$ & $\begin{array}{l}\text { Retractions } \\
(\%)\end{array}$ & $\begin{array}{l}\text { Median } \\
\text { (months) }\end{array}$ & $\begin{array}{l}\mathbf{2 5 \%} \text { quar- } \\
\text { tile }\end{array}$ & $\begin{array}{l}\text { 75\% quar- } \\
\text { tile }\end{array}$ & $\begin{array}{l}\text { Most common } \\
\text { reason }\end{array}$ \\
\hline Algeria & 38 & 3,810 & 0.997 & 19 & 5 & 35 & Plagiarism \\
\hline Egypt & 142 & 52,454 & 0.271 & 15 & 6 & 29 & Plagiarism \\
\hline Jordan & 16 & 11,318 & 0.141 & 12 & 5.5 & 24 & Plagiarism \\
\hline Kuwait & 7 & 6,528 & 0.107 & 13 & 6 & 36 & Duplication \\
\hline Lebanon & 7 & 20,231 & 0.0346 & 15 & 7 & 158 & Duplication \\
\hline Libya & 5 & 1,023 & 0.489 & 11 & 10 & 96 & Duplication \\
\hline Oman & 6 & 5,080 & 0.118 & 6.5 & 0 & 7 & Author related \\
\hline Palestine & 2 & 1,490 & 0.134 & 3 & 1 & 5 & Author related \\
\hline Qatar & 6 & 7,520 & 0.0798 & 15 & 4 & 65 & Duplication \\
\hline Saudi Arabia & 58 & 51,282 & 0.113 & 10 & 2 & 30 & Plagiarism \\
\hline Sudan & 2 & 3,036 & 0.066 & 24.5 & 19 & 30 & Plagiarism \\
\hline Syria & 2 & 1,361 & 0.147 & 14 & 1 & 27 & Plagiarism \\
\hline Tunisia & 26 & 14,303 & 0.182 & 12 & 4 & 31 & Plagiarism \\
\hline $\begin{array}{l}\text { United Arab } \\
\text { Emirates }\end{array}$ & 5 & 7,354 & 0.068 & 9 & 7 & 14 & Plagiarism \\
\hline Total & 322 & 186,790 & 0.172 & 14 & 5 & 30 & \\
\hline
\end{tabular}

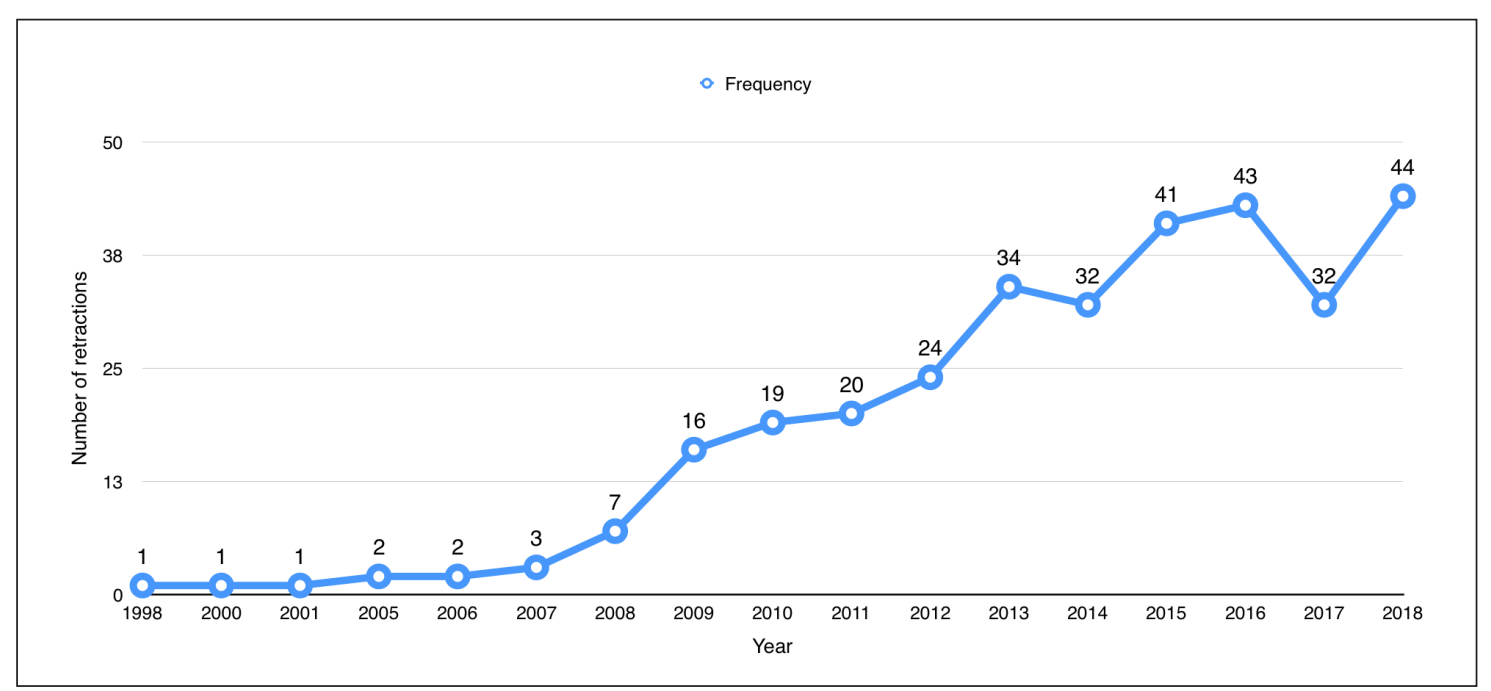

Figure 1. Frequency of retractions of research papers from Arab countries (1998-2018) $(\mathrm{N}=322)$ 